\title{
Current knowledge about the hydrophilic and nanostructured SLActive surface
}

This article was published in the following Dove Press journal:

Clinical, Cosmetic and Investigational Dentistry

2 September 201I

Number of times this article has been viewed

\author{
Ann Wennerberg ${ }^{1,2}$ \\ Silvia Galli² \\ Tomas Albrektsson ${ }^{2,3}$ \\ 'Department of Prosthodontics, \\ Malmö University, Malmö, \\ ${ }^{2}$ Department of Biomaterials, \\ Gothenburg University, Gothenburg, \\ ${ }^{3}$ Department of Materials Science \\ and Technology, Malmö University, \\ Malmö, Sweden
}

\begin{abstract}
This review summarizes the present documentation for the SLActive surface, a hydrophilic and nanostructured surface produced by Straumann Company in Switzerland, and covers the results from 15 in vitro, 17 in vivo, and 16 clinical studies. The SLActive surface is a development of the large grit-blasted and acid-etched SLA surface, and is further processed to a high degree of hydrophilicity. In general, the in vitro and in vivo studies of the SLActive surface demonstrate a stronger cell and bone tissue response than for the predecessor, the SLA surface, produced by the same company. However, in most studies, this difference disappears after 6-8 weeks. In the clinical studies, a stronger bone response was reported for the SLActive surface during the early healing phase when compared with the SLA surface. However, the later biological response was quite similar for the two surfaces and both demonstrated very good clinical results.
\end{abstract}

Keywords: SLActive, surface, in vitro, in vivo, clinical results

\section{Introduction}

We have attempted to summarize current published evidence for the SLActive implant from the Straumann company in Switzerland. The SLActive surface is a relatively recent innovation, with papers published over the last 5 years. This implant design has been launched by Straumann, based on it having a high surface energy, and being more hydrophilic than the previously presented SLA implant from the same company. High surface energy was once suggested by Baier et al $^{1,2}$ to be an important surface characteristic, resulting in stronger bone responses, although one previous attempt to confirm this hypothesis proved unsuccessful, ${ }^{3}$ possibly due to the then tested high surface energy implant losing its physical state when in contact with the tissues. Another explanation may be the fact that surface energy exists at different levels, and the surface energy in this latter study was not high enough. Allegedly, the SLActive surface is supposed to overcome the tissue contamination problem by keeping the implant in a fluid container after surface alteration. The SLA surface is, in principle, produced by coarse grit-blasting with $0.25-0.5 \mathrm{~mm}$ corundum grit at $5 \mathrm{bar}$, followed by acid-etching. ${ }^{4}$ SLActive surfaces are produced with the same sandblasting and acidetching, but they are rinsed under nitrogen protection to prevent exposure to air and then stored in a sealed glass tube containing isotonic $\mathrm{NaCl}$ solution. ${ }^{4}$ Schwarz ${ }^{5}$ claimed that this specific preparation process leads to a hydroxylated/hydrated surface, able to retain the high surface energy by reducing the adsorption of potential contaminants from the atmosphere (eg, hydrocarbons and carbonates).
Correspondence: Ann Wennerberg Department of Prosthodontics, Faculty of Odontology, Malmö University, SE 20506 Malmö, Sweden

Tel +46406658499

Fax +46406658503

Email ann.wennerberg@mah.se 
A computerized search as of April 15, 2011 for scientific papers related to the SLActive surface yielded 15 in vitro studies, 14 in vivo studies in animals, three experimental studies in humans, and 16 clinical studies that will be summarized under these headings. A number of the cited studies investigated what was referred to as a "modified SLA surface" that did not always explicitly state that this modified surface was identical to the sometimes later commercialized SLActive surface. It is not uncommon for commercial companies to test different variations of surfaces before launching one type of surface. The present authors are unaware whether all modified surfaces tested actually are identical to the SLActive surface. In our literature overview, we have decided to use the same terminology as that used by the respective author(s), which is why the investigated implant is termed either SLActive or modified SLA surface in our text.

\section{In vitro studies}

Several in vitro studies have been performed to investigate cellular responses to SLActive surfaces. Many kinds of cells, including human osteoblast-like MG63 cells, human alveolar osteoblasts, and human mesenchymal stem cells from bone marrow, and human periodontal ligament cells, have been cultured on titanium disks with either an SLActive or a modSLA surface and compared with cells cultured on SLA surfaces. Only one study showed an increase of cell adhesion on the SLActive surface within 3 hours, ${ }^{6}$ while most of the studies showed a similar attachment of cells on both SLA and SLActive surfaces..$^{7-9}$ However, a more differentiated phenotype of cells grown on SLActive was noticed compared with SLA, attested by a remarkable increase of alkaline phosphatase activity, osteocalcin, and osteoprotegerin production. ${ }^{4,8,10-13}$ In addition, the production of higher levels of local factors responsible for a bone-forming microenvironment, such as a 10-fold increase of prostaglandin E2 and a 2.5-fold increase of transforming growth factor-beta on SLActive compared with SLA surfaces, ${ }^{4,14,15}$ meant a significant enhancement of numerous gene expressions, associated with transforming growth factor-beta and bone morphogenetic protein signaling pathways. ${ }^{16}$

ModSLA surfaces seem to provide a local noninflammatory microenvironment, since dendritic cells cultivated on modSLA maintain an immature phenotype compared with dendritic cells cultured on SLA surfaces. ${ }^{17}$ Moreover, SLActive surfaces were suggested to enhance angiogenesis induced by osteoblasts, because higher levels of angiogenesis growth factors, ie, vascular endothelial growth factor-A, fibroblast growth factor-2, and epidermal growth factor were found on cells cultivated on SLActive compared with SLA surfaces. ${ }^{18}$ Furthermore, gene expression of several angiogenesis-related factors was found to be increased. ${ }^{19}$

\section{In vivo studies}

The first data on osseointegration of modSLA titanium implants was reported by Buser et al. ${ }^{20}$ The authors compared the percentage of bone to implant contact of SLA and modSLA implants after 2, 4, and 8 weeks of healing, using six miniature pigs receiving 46 implants (23 SLA and 23 modSLA) in a split-mouth design. They found that modSLA implants showed a significantly greater mean percentage of bone to implant contact at $2(49.30 \%$ vs $29.42 \%$; $P=0.017)$ and 4 weeks $(81.91 \%$ vs $66.57 \% ; P=0.011)$ of healing, while no differences were observed at 8 weeks. Similar results were also reported by Bornstein et al, ${ }^{21}$ who placed 30 SLA and 30 SLActive implants in the mandibles of five dogs and reported a significantly higher percentage of bone to implant contact for modSLA implants at 2 weeks of healing $(P<0.05)$, but this difference was no longer evident after 4 weeks. Further evidence was provided by a study performed using the tibia of sheep ${ }^{22}$ and involving 30 implants, 15 SLA and 15 SLActive, retrieved after 3 and 6 weeks. The percentage of bone to implant contact was significantly higher for modSLA implants at 3 weeks, but the difference was not statistically significant after 6 weeks of healing.

Schwarz et $\mathrm{al}^{23-25}$ performed several studies to investigate the performance of SLActive implants, compared with SLA implants. They placed 64 implants, 32 with an SLA surface and 32 with modSLA surface (SLActive) in the upper and lower jaws of four foxhound dogs (16 implants per animal) and assessed histologically, immunohistochemically, and histomorphometrically the bone formation, the peri-implant tissue reaction, angiogenesis, and osteocalcin activity, and the percentage of bone to implant contact after days 1, 4, 7, and 14 of healing. They observed that blood clots around the modSLA surfaces seemed to be stable at 1 day of healing and were substituted by a dense connective tissue after 4 days. Moreover, at day 14, the modSLA implants seemed to be surrounded by firmly attached, mature, parallel-fibered woven bone. In addition, they noticed that after 14 days of healing, modSLA implants were surrounded by well vascularized loose connective tissue exhibiting collagen fibers, that had started to extend and attach in part perpendicularly to the surface, with no clear separation into an inner and an outer zone. A further investigation ${ }^{25}$ confirmed these outcomes in a study performed in 15 beagle dogs involving a total of 240 implants. 
The interfacial biomechanical properties of the SLActive implant surface were compared with the SLA surface in an animal experiment by Ferguson et al. ${ }^{26}$ They placed 162 implants, ie, 81 SLA and 81 modSLA, in the maxilla of 27 miniature pigs in a split-mouth study and analyzed the removal torque and bone-implant interfacial stiffness after weeks 2, 4, and 8 of healing (nine pigs/54 implants per healing time) and found the removal torque values to be on average $8 \%-21 \%$ higher for modSLA $(P=0.003)$ and the interfacial stiffness values on average $9 \%-14 \%$ higher for modSLA implants $(P=0.038)$ at each healing time.

It was hypothesized that the hydrophilic properties noted for modSLA-surface implants may also improve bone formation at buccal dehiscence defects, probably due to stabilization of the blood clot. Schwarz et $\mathrm{al}^{27}$ created acute-type buccal dehiscence defects (height $3 \mathrm{~mm}$, width $3 \mathrm{~mm}$ ) during the placement of 24 implants, ie, 12 SLA and 12 modSLA, in the upper and lower jaws of four beagle dogs and evaluated the bone regeneration after 2 and 12 weeks of healing. They found that modSLA implants exhibited a complete defect fill at 12 weeks following implant placement, while wound healing at SLA implants was merely characterized by the formation of dense connective tissue, without any increase in bone formation. However, it is not clear to what extent a submerged healing procedure may have prevented the collapse of the mucoperiosteal flap into the defect area.

In another experiment, ${ }^{28} 192$ implants (96 with an SLA surface and 96 with an SLActive surface), were placed in 192 sites with standardized buccal dehiscence defects (height $4 \mathrm{~mm}$, width $3 \mathrm{~mm}$ ) and then randomly assigned to a submerged or nonsubmerged healing procedure in the upper and lower jaws of 12 beagle dogs (16 implants per dog). They found that SLActive titanium surfaces promoted bone regeneration (significantly higher percentage of bone to implant contact, new bone height, and new bone fill area) in acute-type buccal dehiscence defects at every stage of healing, and a submerged healing procedure additionally improved the outcome of bone regeneration at follow-up of 1-8 weeks. Schwarz et a ${ }^{29}$ performed a study with the same design to compare bone regeneration in dehiscence-type defects around modSLA surfaces (SLActive) and acid-etched surfaces with a calcium phosphate nanometer particle modification (NanoTite ${ }^{\circledR}$ ), and found that bone filling and area of mineralized tissue was comparable for the two groups. However, modSLA implants revealed significantly higher mean bone to implant contact and new bone height at weeks 2 and 8 of healing. In contrast, Al-Hamdan et al ${ }^{30}$ found similar bone responses to SLActive and Nanotite implants in a beagle dog experiment with a follow-up of 2-8 weeks.
Lai et $\mathrm{al}^{31}$ placed 36 implants, ie, 18 with an SLA surface and 18 with a modSLA surface, in the mandibles of six beagle dogs and left them to heal nonsubmerged for 2, 4, and 8 weeks. One-third of the implants were placed with a $0.5 \mathrm{~mm}$ and one-third with a $1 \mathrm{~mm}$ bone gap around the coronal $5 \mathrm{~mm}$ of the implants, while the remaining one-third was inserted without a gap. Histological observation and histomorphometric analysis showed a significantly greater percentage of bone to implant contact, newly formed bone, and defect filling with modSLA implants compared with SLA implants at weeks 2 and 4 of healing, but no significant differences were found between the two groups at week 8 . No differences in healing patterns were found for the two defect sizes.

Liñares et $\mathrm{al}^{32}$ analyzed the effect of loading time on modSLA implants. They placed 24 implants with a modSLA surface after tooth extraction in the mandibles of six miniature pigs (four implants in each animal) according to a splitmouth design, ie, the implants were loaded after four weeks of healing in one side of the mandible, while on the contralateral side, the implants were loaded immediately after placement. After 8 weeks of loading, the animals were sacrificed and 21 implants were histologically and histomorphometrically analyzed, with the percentage of bone to implant contact and the mean distance of the implant shoulder to the first bone to implant contact being similar for both groups.

Mardas et $\mathrm{al}^{33}$ operated on $36 \mathrm{New}$ Zealand white rabbits, comprising 12 with induced osteoporosis, 12 with osteoporosis treated with alendronate, and 12 healthy controls, and evaluated bone formation histomorphometrically after 30 and 120 days. A guided bone regeneration procedure involving titanium domes with two different surfaces, ie, one SLA and one modSLA (SLActive), were placed over the prepared bone defects. The investigators reported that newly formed total bone, newly formed mineralized bone, and bone to implant contact were higher at the modSLA-treated sites during all the experimental periods. Therefore, the use of modSLA may further promote extraskeletal bone formation and osseointegration in healthy and osteoporotic-like conditions.

Three papers ${ }^{34-36}$ reported experimental in vivo studies in humans, and investigated for the first time the sequence of events during early osseointegration in human volunteers. Lang et $\mathrm{a}^{34}$ placed 49 solid screw-shaped implants with a diameter of $2.8 \mathrm{~mm}$ and a length of $4 \mathrm{~mm}$, either with an SLA surface or an SLActive surface in the mandibular retromolar area of 28 human volunteers and retrieved them after days 7 , 14,28 , and 42 of submerged healing. Although all the devices healed uneventfully, only 30 (61\%) specimens were available 
for analysis due to the difficulty in harvesting. At both days 7 and 14 of healing, no differences were observed between the two surfaces and the percentage of bone to implant contact increased from $6 \%$ to $12.2 \%$ for SLA and from $6 \%$ to $14.8 \%$ for SLActive. The 28-day specimens showed a significant increase of bone to implant contact of at least three-fold from the 7-day examination, with a bone to implant contact of $32.4 \%$ for SLA and $48.3 \%$ for SLActive, representing a statistically significant difference between the two surfaces and in favor of the SLActive surface. Six weeks after insertion, the percentage of bone to implant contact had further increased, reaching $62 \%$ for both implant surfaces, without any difference between them.

The same cohort was included in another study ${ }^{35}$ in which the new bone formation and the role of bone debris and bone particles during the early healing stages were assessed. New bone apposition was higher on SLActive screws after weeks 2 and 4, but the difference did not reach statistical significance. Furthermore, with the same protocol, ${ }^{36} 18$ solid screwtype cylindrical titanium implants, $4 \mathrm{~mm}$ long and $2.8 \mathrm{~mm}$ wide, either with an SLA or with an SLActive surface, were inserted in the mandibles of nine volunteers. The authors found that genes had the same pattern of expression around the two different surfaces at day 4, while at day 7 several functionally important gene categories were overrepresented in the SLActive specimens, including genes involved in bone mineralization/ossification, vascular endothelial growth factor signaling, focal adhesion and mitogen-activated protein kinase signaling, as was the category of extracellular space localization genes (osteogenesis and angiogenesis-associated gene expression). At day 14, the gene expression profile was associated with more mature wound healing on both surfaces, with bone morphogenetic protein signaling upregulated also on SLA surfaces.

\section{Clinical studies}

Randomized controlled clinical trials comparing SLA and SLActive are still few. One is the pilot study of Oates et al, ${ }^{37}$ who treated 31 patients with 62 implants, with either an SLA or an SLActive surface, placed posteriorly in both jaws. Each patient received one implant of each type in the same arch. Resonance frequency analysis and clinical evaluations were carried out at weeks $0,1,2,3,4,5$, and 6 after implant placement. All implants were integrated, but six of them were excluded from resonance frequency analysis because of protocol violation. Overall, the implant surface was not significant for implant stability after 6 weeks, but SLActive implants showed a significant change in the pattern of stability at the 2-week point in the mandible and the 3-week point in the maxilla, while the SLA implants showed this change at week 4 in the mandible but not in the maxilla.

Han et $\mathrm{al}^{38}$ treated 23 patients with 25 Straumann bone level implants, 12 regular neck SLA with a diameter of $4.1 \mathrm{~mm}$, eight SLActive with a diameter of $4.1 \mathrm{~mm}$, and five wide neck SLA with a diameter of $4.8 \mathrm{~mm}$. The resonance frequency analysis, performed at implant installation and at 4 days, and at weeks 1, 2, 3, 4, 6, 8, and 12 post-surgery showed a similar pattern for all implants, with a slight decrease of implant stability quotient values in the first 3-4 weeks of healing and the lowest value at the third week, followed thereafter by a steady increase. The mean implant stability quotient values for regular neck SLA, SLActive, and wide neck SLA were, respectively, 72.6, 75.7, and 74.4 at implant placement, 69.9, 71.4, and 74.4 at 3 weeks (the lowest values), and 76.5, 78.8, and 77.8 after 12 weeks.

In another investigation, ${ }^{39} 22$ patients with bilateral tooth loss in the same jaws were rehabilitated with 96 dental implants, 48 SLA and 48 SLActive, such that all patients received at least one SLA and one SLActive implant. Prosthetic loading was initiated after 8 weeks of healing in the mandible and after 12 weeks in the maxilla. No patients were lost to follow-up and only one SLActive implant failed after 3 weeks of placement, giving an overall survival rate 1 year after loading of $100 \%$ for SLA and $97.91 \%$ for SLActive (difference not significant). Resonance frequency analysis was performed at surgery, and weeks 1, 3, and 6 later, but there was no statistically significant interaction between SLA and modSLA implants. Mean bone loss at the loading stage (baseline, implant insertion), measured for 93 implants and only by means of panoramic X-rays, was found to be $0.22 \pm 0.06 \mathrm{~mm}$ for SLA and $0.18 \pm 0.05 \mathrm{~mm}$ for SLActive, and after 1 year of function, with a marginal bone loss of $0.46 \pm 0.07 \mathrm{~mm}$ around SLA and $0.43 \pm 0.11 \mathrm{~mm}$ around SLActive implants.

In a clinical prospective study, ${ }^{40} 20$ patients, who had been treated at least 6 months previously with radiochemotherapy in the oral region, were rehabilitated with 102 implants, 50 SLA and 52 SLActive, randomly assigned according to a split-mouth design. The prosthetic load was carried out after 6 weeks in the mandible and 10 weeks in the maxilla. There was one patient dropout (five implants) due to recurrence of cancer and therefore 97 implants were followed for an average time of 14.4 months. Survival rate was $96 \%$ for the SLA, because two implants were lost before loading, and $100 \%$ for SLActive. The amount of bone loss was evaluated only by orthopanoramic radiography and reported as 
a mean only, ie, $0.4 \mathrm{~mm}$ medially and $0.4 \mathrm{~mm}$ distally for SLA implants and $0.3 \mathrm{~mm}$ medially and $0.3 \mathrm{~mm}$ distally for SLActive implants, although whether the resolution level of mean orthopanoramic radiography is satisfactory for a statistical analysis can be seriously debated.

Ganeles et $\mathrm{al}^{41}$ placed 383 SLActive implants (197 immediately nonocclusive loaded and 186 loaded with nonocclusive restoration after 28-34 days) in 266 patients. Change in bone levels was assessed for 323 implants (missing data for 60 implants) by mean of standardized periapical radiographs, taken at baseline, at time of permanent restoration (20-23 weeks post-surgery) and after 5 and 12 months. The 5 -month results ${ }^{42}$ revealed a mean bone level change from baseline (baseline not specified) that was $0.81 \pm 0.89 \mathrm{~mm}$ and $0.56 \pm 0.73 \mathrm{~mm}$ in the immediate and early loading group, respectively, with a statistically significant difference. The mean bone level change at 12 months was $0.90 \pm 0.90 \mathrm{~mm}$ for immediate loading and $0.77 \pm 0.93 \mathrm{~mm}$ for the early loading, showing a significant difference between treatment groups. However, implantation depth was different, with immediately loaded implants placed, on average, $0.3 \mathrm{~mm}$ deeper than later loaded implants. The frequency of bone loss $>2 \mathrm{~mm}$ was low overall, but three-fold higher in the immediately loaded group. Bone gain was noted for $16 \%$ of the implants. Bone loss was significantly correlated with treatment center, implant length and implant position. Implant survival at 12 months was claimed to be $98 \%$ in the immediate group (four implants lost) and 97\% in the early group (six implants lost), with no implant failures reported in type IV bone (where $7.3 \%$ of implants were placed). However, the dropout rate was not reported.

Bornstein et $\mathrm{al}^{43}$ inserted 56 SLActive implants in the posterior mandible of 39 patients and loaded 54 of the implants (96.4\%) after 21 days of healing, while two were left unloaded for an additional 3 weeks because they were considered "spinners". At 6 months' follow-up all implants were osteointegrated (including the two "spinners") and mean bone loss from baseline (implant placement), measured on periapical radiographs, was $0.24 \mathrm{~mm}$. The implant stability quotient values increased steadily during the observation time, being on average 74.44 at implant placement and reaching 83.82 by week 26 . Follow-up at 3 years ${ }^{44}$ revealed no implant failure and a mean bone loss of $0.12 \mathrm{~mm}$ from the baseline with no implant, with a bone loss of more than $1 \mathrm{~mm}$. The authors claimed that there were no dropouts at any time point.

In a two-center prospective study, ${ }^{45} 56$ patients were consecutively enrolled and received 89 SLActive implants. Loading after 21 days of healing was planned, both in the upper and lower jaw. After 21 days of healing, two implants were considered to be nonintegrated and removed before loading, two implants were considered "spinners" and were given 3 weeks of additional healing, and one implant in one patient was lost to follow-up. After 24 months, marginal bone loss from the baseline of implant placement, assessed by mean of periapical radiographs, was $0.2 \mathrm{~mm}$, with 25 implants having a loss of $0.3-1.0 \mathrm{~mm}$, no implant with a bone loss $>1 \mathrm{~mm}$, and 39 implants with a bone gain.

Roccuzzo et $\mathrm{al}^{46}$ placed 35 implants in the maxillary posterior region of 35 consecutively enrolled patients. Of these, 29 implants were loaded with a provisional prosthesis in occlusion after $21 \pm 2$ days, while the six remaining implants were left healing for another 3-4 weeks, since they rotated slightly at day 21 . After 1 year of follow-up, there were no patient dropouts and no implant losses. Bone loss from baseline (abutment connection), derived from measurements on periapical radiographs, was reported only as a mean value of $0.22 \pm 0.35 \mathrm{~mm}$.

Rossi et $\mathrm{al}^{47}$ placed 40 SLActive short $(6 \mathrm{~mm})$ implants in 35 consecutive patients, 10 of whom were heavy smokers, and loaded them after 6 weeks of healing with single crowns and followed them up for 2 years. The dropout rate was not revealed. They found a 95\% survival rate after 2 years, due to two implants being lost before loading, with a mean resonance frequency analysis value of $74.8 \pm 6.1$ at the 6 -week evaluation. Bone loss from implant placement was noticed on periapical standardized radiographs for 35 implants and was $0.75 \mathrm{~mm}$, reported only as a mean of $0.34 \pm 0.38 \mathrm{~mm}$ before loading and increased by $0.23 \pm 0.33$ in the first year of loading, and by another $0.21 \pm 0.39 \mathrm{~mm}$ in the second year of loading.

In another paper, ${ }^{48} 11$ patients (nine edentulous and two partially edentulous) were treated with bilateral sinus floor augmentation, performed with synthetic biphasic calcium phosphate on one side and with deproteinized bovine bone on the other side (randomly selected), and the placement of 62 SLActive implants after 8 months of healing. Time of the loading was not reported. The overall survival rate (no dropouts) was $96.8 \%$, since two implants were lost, one made of each material, and the success rate was $91.7 \%$ for biphasic calcium phosphate and $95.7 \%$ for deproteinized bovine bone. The mean marginal bone loss from baseline (time of the delivery of the fixed prosthesis) to the 1-year follow-up was reported to be $0.29 \pm 0.10 \mathrm{~mm}$ for implants placed in deproteinized bovine bone (23 implants), $0.43 \pm 0.20 \mathrm{~mm}$ for implants placed in biphasic calcium phosphate ( 24 implants), and $0.52 \pm 0.27 \mathrm{~mm}$ for implants placed in the native bone (15 implants). 
In a case report, Marchetti et $\mathrm{al}^{49}$ treated a 59-year-old patient with a severely atrophied maxilla using a Le Fort I osteotomy and interpositional iliac bone graft and, 13 weeks later, with the placement of seven immediately-loaded SLActive implants. After 20 months of follow-up, they found no implant failure and minimal bone loss, measured on periapical radiograms (baseline implant placement), as an average of 0.78 (range $0-1.75$ ) $\mathrm{mm}$.

Stoker et $a{ }^{50}$ placed 248 SLActive implants in the intraforaminal area of atrophic mandibles in 124 patients and loaded them immediately with an implant-retained overdenture and evaluated them for a mean period of 2 years (12-40 months). The dropout rate was not reported and the survival rate at the end of the evaluation period was $98.8 \%$, with only three implants lost. During the healing phase, the implant stability quotient value increased significantly.

Al-Nawas et $\mathrm{al}^{51}$ investigated whether small diameter (3.3 mm) implants made from titanium-zirconium alloy performed similarly to titanium Grade IV small diameter implants, with the same SLActive surface. Ninety-one patients were enrolled and received 182 small diameter implants, one for each type, in the interforaminal region of the mandible and were rehabilitated with implant retained overdentures after 6-8 weeks. Of these patients, 87 were available for the study period of 12 months. Three implants were lost and two implants (in the same patient) had recurrent peri-implant infection. The mean peri-implant bone level from the day of the surgery was $0.34 \pm 0.54 \mathrm{~mm}$ for titaniumzirconium and $0.31 \pm 0.56 \mathrm{~mm}$ for titanium Grade IV after 12 months, but most of the changes occurred within the first 6 months. Nevertheless, because the two types of implants were made of different alloys, the authors of the present paper are uncertain whether the two surfaces are similar to or differ from SLActive surfaces produced on other materials.

Bergkvist et $\mathrm{al}^{52}$ investigated the relationship between bone mineral density assessed by computed tomography scans before implant placement, the implant stability measured at implant placement, and also the marginal bone around immediately loaded implants. Twenty-one patients were sequentially enrolled and 137 SLActive implants were placed and immediately loaded both in the maxilla and mandible, and were followed for 1 year. At 1-year examination, the survival rate was $100 \%$, but the patient dropout rate was not reported. The change in mean marginal bone level from baseline was $1.18 \pm 0.98 \mathrm{~mm}$ in the maxilla and $1.15 \pm 1.23 \mathrm{~mm}$ in the mandible, with almost $80 \%$ of the surfaces (medial and distal) having a marginal bone loss $<1 \mathrm{~mm}$.

\section{Discussion}

\section{Characteristics of SLActive surface that may explain tissue reactions}

The SLActive implant is marketed on the basis of its high surface energy. However, in reality, there are several differences between SLA and SLActive surfaces that are just as likely as high surface energy to explain experimental or possible clinical differences between the two surfaces, eg, the differences in microroughness and nanoroughness between SLA and SLActive. ${ }^{53}$ Whereas SLA surfaces have changed from older batches with an SA (average height deviation from a mean plane) of about $1.5 \mu \mathrm{m}$ and an Sdr (surface enlargement due to surface topography as compared with a flat reference area) $\%$ of 34 over to an Sa of $1.75 \mu \mathrm{m}$ and an $\mathrm{Sdr} \%$ of $97 \%$, the SLActive surface has an even greater Sdr\% of 143, if with a similar Sa value of $1.78 \mu \mathrm{m}$. In this case, the surface difference indicates that SLActive has a much greater number of peaks/ valleys across the surface compared with SLA (Figure 1A and B). Furthermore, a distinct difference in nanoroughness between SLA and SLActive was noticed, with the latter surface
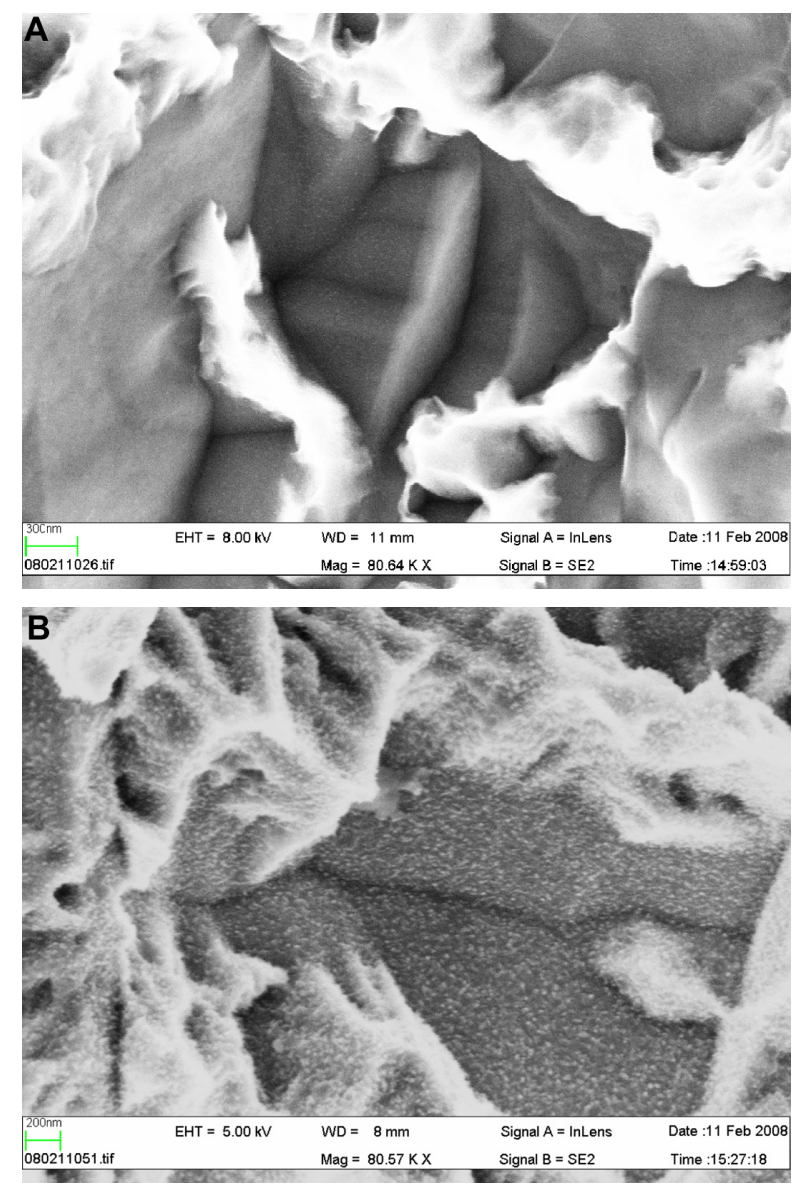

Figure I (A) Scanning electron microscopic image of a SLA implant, 80,000 × magnification. No distinct nanostructures can be observed. (B) Scanning electron microscopic image of a SLActive implant, 80,000 × magnification. Distinct nanostructures can be observed. 

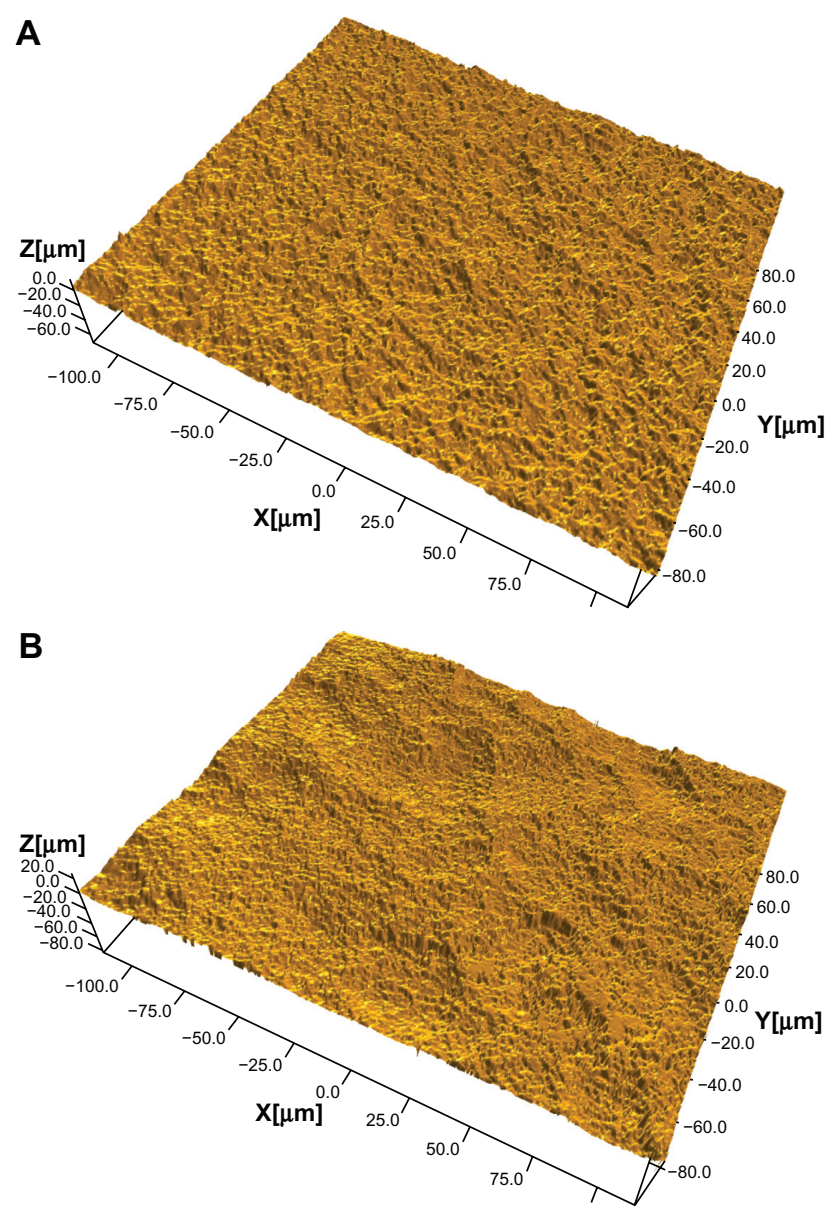

Figure 2 (A) An SLA implant, flank area. (B) An SLActive implant, flank area The image demonstrates a complex surface topography with several wavelengths included.

having a very clear nanoroughness pattern in contrast with the former surface ${ }^{53}$ (Figure 2A and B).

\section{Experimental findings of in vitro/in vivo studies}

Most in vitro and in vivo studies report a stronger short-term bone response to SLActive implants compared with SLA implants, but the difference disappears in many in vivo cases during the first 6-8 weeks.

\section{Findings from human experimental studies}

Three human experimental studies performed under the guidance of a university ethics committee documented a stronger bone response to SLActive compared with SLA implants at weeks 2 and 4 of follow-up, but no differences between the two implants at 6 weeks of follow-up. In our opinion, these human experimental studies failed to provide strong support for the alleged clinical advantage of SLActive implants, due to the differences having already leveled out at 6 weeks.

\section{Findings from clinical studies}

Some of the clinical studies measured bone loss only with orthopantograms which is a clear methodological shortcoming. Furthermore, the baseline for radiography in many studies was the time of loading, indicating that any bone loss preceding the time of loading is neglected. Naturally, the later the loading, the larger the potentially hidden bone loss. However, it must be noted that there is no consensus as yet about the most appropriate time for baseline radiography, hence an underestimation of true bone loss figures are not necessarily more common in clinical SLActive reports than for other clinical materials. There were other clinical papers on the SLActive implant where only mean bone loss was reported, which is a severe shortcoming of those papers because the minimal requirement is to present either standard deviations or separate those implants with $>2 \mathrm{~mm}$ and $>3 \mathrm{~mm}$ of bone loss from the rest of the materials, given that such implants may not be deemed successful.

\section{Results from comparative clinical studies}

Some clinical studies were properly randomized and the measured outcomes were either similar between SLA and SLActive or some early advantages at short-term follow-up were noticed for SLActive implants. However, reported differences in bone loss were very small and only reported by a couple of studies.

\section{Conclusion}

There are many published experimental and clinical studies of the SLActive implant. Most experimental studies indicate stronger bone responses to the SLActive surface compared with the SLA surface, at least in the first few weeks after implant placement. From a clinical viewpoint, many studies have been published where SLA and SLActive surfaces have been compared with one another and are quite positive. However, the clinical differences noted between the two types of surfaces are very small, and it is the opinion of the present authors that, based on the collective evidence from our present review, there are few indications supporting one implant type over another. Having said this, within the limitations of the maximal 
three-year observation period, SLActive surfaces seem to perform adequately and may, like SLA surfaces, be regarded as representing a well performing modern oral implant system.

\section{Disclosure}

The authors report no conflicts of interest in this work.

\section{References}

1. Baier RE, Meyer AE, Natiella JR, Natiella RR, Carter JM. Surface properties determine bioadhesive outcomes: Methods and results. J Biomed Mater Res. 1984;18:337-355.

2. Baier RE, De Palma VA. Electrode-less glow discharge cleaning and activation of high energy substrates to ensure their freedom from organic contamination and their receptivity for adhesives and coatings. Technical Report CAQL NO 176, Internal Research Work Authorization No 7145-7176. Buffalo NY: Cornell Aeronautical Laboratory Inc, Cornell University; 1970.

3. Carlsson LV, Albrektsson T, Berman C. Bone response to plasma-cleaned titanium implants. Int $J$ Oral Maxillofac Implants. 1989;4:199-204.

4. Zhao G, Schwartz Z, Wieland M, et al. High surface energy enhances cell response to titanium substrate microstructure. J Biomed Mater Res A. 2005;74:49-58.

5. Schwarz F, Wieland M, Schwartz R, et al. Potential of chemically modified hydrophilic surface characteristics to support tissue integration of titanium dental implants. J Biomed Mater Res B Appl Biomater. 2009;88:544-557.

6. Lai HC, Zhuang LF, Liu X, Wieland M, Zhang ZY, Zhang ZY. The influence of surface energy on early adherent events of osteoblast on titanium substrates. J Biomed Mater Res A. 2010;93:289-296.

7. Wall I, Donos N, Carlqvist K, Jones F, Brett P. Modified titanium surfaces promote accelerated osteogenic differentiation of mesenchymal stromal cells in vitro. Bone. 2009;45:17-26.

8. Mamalis AA, Silvestros SS. Analysis of osteoblastic gene expression in the early human mesenchymal cell response to a chemically modified implant surface: an in vitro study. Clin Oral Implants Res. 2011;22:530-537.

9. Qu Z, Rausch-Fan X, Wieland M, Matejka M, Schedle A. The initial attachment and subsequent behavior regulation of osteoblasts by dental implant surface modification. $J$ Biomed Mater Res A. 2007;1;82:658-668.

10. Masaki C, Schneider GB, Zaharias R, Seabold D, Stanford C. Effects of implant surface microtopography on osteoblast gene expression. Clin Oral Implants Res. 2005;16:650-656.

11. Klein MO, Bijelic A, Toyoshima T, et al. Long-term response of osteogenic cells on micron and submicron- scale-structured hydrophilic titanium surfaces: Sequence of cell proliferation and cell differentiation. Clin Oral Implants Res. 2010;21:642-649.

12. Mamalis AA, Markopoulou C, Vrotsos I, Koutsilirieris M. Chemical modification of an implant surface increases osteogenesis and simultaneously reduces osteoclastogenesis: an in vitro study. Clin Oral Implants Res. 2011;22:619-626.

13. Fang M, Olivares-Navarrete R, Wieland M, Cochran DL, Boyan BD, Schwartz Z. The role of phospholipase D in osteoblast response to titanium surface microstructure. J Biomed Mater Res A. 2010;93: 897-909.

14. Rausch-Fan X, Qu Z, Wieland M, Matejka M, Schedle A. Differentiation and cytokine synthesis of human alveolar osteoblasts compared to osteoblast-like cells (MG63) in response to titanium surfaces. Dent Mater. 2008;24:102-110.
15. Zhao G, Raines AL, Wieland M, Schwartz Z, Boyan BD. Requirement for both micron- and submicron scale structure for synergistic responses of osteoblasts to substrate surface energy and topography. Biomaterials. 2007;28:2821-2829.

16. Vlacic-Zischke J, Hamlet SM, Friis T, Tonetti MS, Ivanovski S. The influence of surface microroughness and hydrophilicity of titanium on the up-regulation of TGFb/BMP signalling in osteoblasts. Biomaterials. 2011;32:665-671.

17. Kou PM, Schwartz Z, Boyan BD, Babensee JE. Dendritic cell responses to surface properties of clinical titanium surfaces. Acta Biomater. 2011;7:1354-1363.

18. Raines AL, Olivares-Navarrete R, Wieland M, Cochran DL, Schwartz Z, Boyan BD. Regulation of angiogenesis during osseointegration by titanium surface microstructure and energy. Biomaterials. 2010;31:4909-4917.

19. An N, Schedle A, Wieland M, Andrukhov O, Matejka M, Rausch-Fan X. Proliferation, behavior, and cytokine gene expression of human umbilical vascular endothelial cells in response to different titanium surfaces. J Biomed Mater Res A. 2010;93:364-372.

20. Buser D, Broggini N, Wieland M, et al. Enhanced bone apposition to a chemically modified SLA titanium surface. J Dent Res. 2004;83:529-533.

21. Bornstein MM, Valderrama P, Jones AA, Wilson TG, Seibl R, Cochran DL. Bone apposition around two different sandblasted and acid-etched titanium implant surfaces: A histomorphometric study in canine mandibles. Clin Oral Implants Res. 2008;19:233-241.

22. Abdel-Haq J, Karabuda CZ, Arısan V, Mutlu Z, Kürkçü M. Osseointegration and stability of a modified sand-blasted acid-etched implant: An experimental pilot study in sheep. Clin Oral Implants Res. 2011;22:265-274.

23. Schwarz F, Herten M, Sager M, Wieland M, Dard M, Becker J. Histological and immunohistochemical analysis of initial and early osseous integration at chemically modified and conventional SLA titanium implants: Preliminary results of a pilot study in dogs. Clin Oral Implants Res. 2007;18:481-488.

24. Schwarz F, Herten M, Sager M, Wieland M, Dard M, Becker J. Histological and immunohistochemical analysis of initial and early subepithelial connective tissue attachment at chemically modified and conventional SLA ${ }^{\circledR}$ titanium implants. A pilot study in dogs. Clin Oral Investig. 2007;11:245-255.

25. Schwarz F, Ferrari D, Herten M, et al. Effects of surface hydrophilicity and microtopography on early stages of soft and hard tissue integration at non-submerged titanium implants: An immunohistochemical study in dogs. J Periodontol. 2007;78:2171-2184.

26. Ferguson SJ, Broggini N, Wieland M, et al. Biomechanical evaluation of the interfacial strength of a chemically modified sandblasted and acid-etched titanium surface. J Biomed Mater Res A. 2006;78: 291-297.

27. Schwarz F, Herten M, Sager M, Wieland M, Dard M, Becker J. Bone regeneration in dehiscence-type defects at chemically modified (SLActives) and conventional SLA titanium implants: A pilot study in dogs. J Clin Periodontol. 2007;34:78-86.

28. Schwarz F, Sager M, Ferrari D, Herten M, Wieland M, Becker J. Bone regeneration in dehiscence-type defects at non-submerged and submerged chemically modified (SLActives) and conventional SLA titanium implants: An immunohistochemical study in dogs. $J$ Clin Periodontol. 2008;35:64-75.

29. Schwarz F, Sager M, Kadelka I, Ferrari D, Becker J. Influence of titanium implant surface characteristics on bone regeneration in dehiscence-type defects: An experimental study in dogs. J Clin Periodontol. 2010;37:466-473.

30. Al-Hamdan K, Al-Moaber SH, Junker R, Jansen JA. Effect of implant surface properties on peri-implant bone healing: A histological and histomorphometric study in dogs. Clin Oral Implants Res. 2011;22:399-405. 
31. Lai HC, Zhuang LF, Zhang ZY, Wieland M, Liu X. Bone apposition around two different sandblasted, large-grit and acid-etched implant surfaces at sites with coronal circumferential defects: An experimental study in dogs. Clin Oral Implants Res. 2009;20: 247-253.

32. Liñares A, Mardas N, Dard M, Donos N. Effect of immediate or delayed loading following immediate placement of implants with a modified surface. Clin Oral Implants Res. 2011;22:38-46.

33. Mardas N, Schwarz F, Petrie A, Hakimi AR, Donos N. The effect of SLActive surface in guided bone formation in osteoporotic-like conditions. Clin Oral Implants Res. 2011;22:406-415.

34. Lang NP, Salvi GE, Huynh-Ba G, Ivanovski S, Donos N, Bosshardt DD. Early osseointegration to hydrophilic and hydrophobic implant surfaces in humans. Clin Oral Implants Res. 2011;22:349-356.

35. Bosshardt DD, Salvi GE, Huynh-Ba G, Ivanovski S, Donos N, Lang NP. The role of bone debris in early healing adjacent to hydrophilic and hydrophobic implant surfaces in man. Clin Oral Implants Res. 2011;22:357-364.

36. Donos N, Hamlet S, Lang NP, et al. Gene expression profile of osseointegration of a hydrophilic compared with a hydrophobic microrough implant surface. Clin Oral Implants Res. 2011;22:365-372.

37. Oates TW, Valderrama P, Bischof M, et al. Enhanced implant stability with a chemically modified SLA ${ }^{\circledR}$ surface: A randomized pilot study. Int J Oral Maxillofac Implants. 2007;22:755-760.

38. Han J, Lulic M, Lang NP. Factors influencing resonance frequency analysis assessed by Osstell mentor during implant tissue integration: II. Implant surface modifications and implant diameter. Clin Oral Implants Res. 2010;21:605-611.

39. Karabuda ZC, Abdel-Haq J, Artsan V. Stability, marginal bone loss and survival of standard and modified sand-blasted, acid-etched implants in bilateral edentulous spaces: A prospective 15-month evaluation. Clin Oral Implants Res. 2011;22:840-849.

40. Heberer S, Kilic S, Hossamo J, Raguse JD, Nelson K. Rehabilitation of irradiated patients with modified and conventional sandblasted acidetched implants: Preliminary results of a split-mouth study. Clin Oral Implants Res. 2011;22:546-551.

41. Ganeles J, Zöllner A, Jackowski J, ten Bruggenkate C, Beagle J, Guerra F. Immediate and early loading of Straumann implants with a chemically modified surface (SLActive) in the posterior mandible and maxilla: 1-year results from a prospective multicenter study. Clin Oral Implants Res. 2008;19:1119-1128.

42. Zöllner A, Ganeles J, Korostoff J, Guerra F, Krafft T, Brägger U. Immediate and early non-occlusal loading of Straumann implants with a chemically modified surface (SLActive) in the posterior mandible and maxilla: Interim results from a prospective multicenter randomizedcontrolled study. Clin Oral Implants Res. 2008;19:442-450.
43. Bornstein MM, Hart CN, Halbritter SA, Morton D, Buser D. Early loading of nonsubmerged titanium implants with a chemically modified sand-blasted and acid-etched surface: 6-month results of a prospective case series study in the posterior mandible focusing on peri-implant crestal bone changes and implant stability quotient (ISQ) values. Clin Implant Dent Relat Res. 2009;11:338-347.

44. Bornstein MM, Wittneben JG, Brägger U, Buser D. Early loading at 21 days of non-submerged titanium implants with a chemically modified sandblasted and acid-etched surface: 3 -year results of a prospective study in the posterior mandible. J Periodontol. 2010;81:809-818.

45. Morton D, Bornstein MM, Wittneben JG, et al. Early loading after 21 days of healing of nonsubmerged titanium implants with a chemically modified sandblasted and acid-etched surface: Two-year results of a prospective two-center study. Clin Implant Dent Relat Res. 2010;12:9-17.

46. Roccuzzo M, Wilson TG, Jr. A prospective study of 3 weeks' loading of chemically modified titanium implants in the maxillary molar region: 1-year results. Int J Oral Maxillofac Implants. 2009;24:65-72.

47. Rossi F, Ricci E, Marchetti C, Lang NP, Botticelli D. Early loading of single crowns supported by 6-mm-long implants with a moderately rough surface: A prospective 2-year follow-up cohort study. Clin Oral Implants Res. 2010;21:937-943.

48. Lindgren C, Mordenfeld A, Hallman M. A prospective 1-year clinical and radiographic study of implants placed after maxillary sinus floor augmentation with synthetic biphasic calcium phosphate or deproteinized bovine bone. Clin Implant Dent Relat Res. 2010. [Epub ahead of print.]

49. Marchetti C, Felice P, Lizio G, Rossi F. Le Fort I osteotomy with interpositional graft and immediate loading of delayed modified SLActive surface dental implants for rehabilitation of extremely atrophied maxilla: A case report. J Oral Maxillofac Surg. 2009;67:1486-1494.

50. Stoker GT, Wismeijer D. Immediate loading of two implants with a mandibular implant-retained overdenture: A new treatment protocol. Clin Implant Dent Relat Res. 2009. [Epub ahead of print.]

51. Al-Nawas B, Brägger U, Meijer HJ, et al. A double-blind randomized controlled trial (RCT) of Titanium-13Zirconium versus Titanium Grade IV small-diameter bone level implants in edentulous mandibles - Results from a 1-year observation period. Clin Implant Dent Relat Res. 2011. [Epub ahead of print.]

52. Bergkvist G, Koh KJ, Sahlholm S, Klintström E, Lindh C. Bone density at implant sites and its relationship to assessment of bone quality and treatment outcome. Int $J$ Oral Maxillofac Implants. 2010;25:321-328

53. Wennerberg A, Albrektsson T. On implant surfaces: A review of current knowledge and opinions. Int J Oral Maxillofac Implants. 2010;25:63-74.
Clinical, Cosmetic and Investigational Dentistry

\section{Publish your work in this journal}

Clinical, Cosmetic and Investigational Dentistry is an international, peer-reviewed, open access, online journal focusing on the latest clinical and experimental research in dentistry with specific emphasis on cosmetic interventions. Innovative developments in dental materials, techniques and devices that improve outcomes and patient satisfac-

\section{Dovepress}

tion and preference will be highlighted. The manuscript management system is completely online and includes a very quick and fair peerreview system, which is all easy to use. Visit http://www.dovepress. $\mathrm{com} /$ testimonials.php to read real quotes from published authors. 